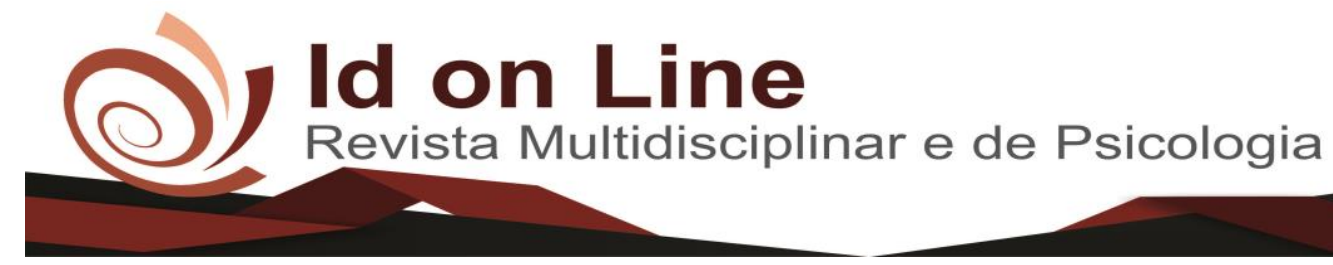

DOI: 10.14295/idonline.v14i50.2466

Artigo

\title{
As Contribuições da Capoeira na Educação
}

\author{
Tiago da Silva ${ }^{1}$; Paula Veruska Alexandre de Lima²; Raquel da Silva Mateus ${ }^{3}$; \\ Edilne Maria Luna Bacurau Saraiva ${ }^{4}$ Juliana Alves Santana ${ }^{5}$
}

Resumo: A capoeira nos tempos atuais vem crescendo em quantidades de adeptos a sua prática, tanto no Brasil como em outros países, trabalhando educação tanto formal, como informal e não formal. Os praticantes desta arte unem um corpo mais saudável e uma mente mais aberta. É um esporte muito completo, unindo: força, flexibilidade e equilíbrio num jogo que é quase uma dança, não fossem pelos golpes deferidos pelos capoeiristas. O intuito deste trabalho de pesquisa é analisar através da história da capoeira a identidade cultural afro-brasileira, reconhecimento da mesma como luta, influências regionais cearenses para o crescimento da arte genuinamente brasileira e a força da Capoeira como educação na formação cidadã no exercício da cidadania. A população e a amostra da pesquisa serão qualitativas, sendo uma pesquisa bibliográfica, foram usados artigos e livros para levantar informações teóricas e históricas sobre o assunto para um questionamento sobre a capoeira como patrimônio brasileiro, cultura, luta e educação. Serão utilizados para as escolhas desses artigos aqueles que mais se adequam ao que se deseja questionar e levantar informações teóricas suficientes sobre o assunto, no intuito de ser o mais claro possível para não chegar às contradições que surgem em relação ao estudo da história da capoeira e sua origem, buscando, além disso, a importância da mesma para a formação educacional, cultural, histórico, social, difusora da língua portuguesa e identidade do povo brasileiro.

Palavras-Chave: Capoeira, Educação, História e Luta.

\section{Capoeira's Contributions in Education}

\begin{abstract}
Capoeira nowadays has been growing in numbers of followers to its practice, both in Brazil and in other countries, working both formal, informal and non-formal education. Practitioners of this art unite a healthier body and a more open mind. It is a very complete sport, uniting: strength, flexibility and balance in a game that is almost a dance, were it not for the blows deferred by capoeiristas. The aim of this research work is to analyze, through the history of capoeira, the Afro-Brazilian cultural identity, recognition of it as a struggle, regional influences from Ceará for the growth of genuinely Brazilian art and the strength of Capoeira as an education in citizen training in the exercise of citizenship . The population and the sample of the research will be qualitative, being a bibliographic research, articles and books were used to raise theoretical and historical information on the subject for a questioning about capoeira as Brazilian heritage, culture, fight and education. For the choices of these articles, those that are best suited to what is to be questioned and sufficient theoretical information on the subject will be used, in order to be as clear as possible so as not to arrive at the contradictions that arise in relation to the study of the history of capoeira and its origin, seeking, in addition, its importance for the educational, cultural, historical, social formation, diffusing the Portuguese language and the identity of the Brazilian people.
\end{abstract}

Keywords: Capoeira, Education, History and Fight.

\footnotetext{
${ }^{1}$ Mestrando em Ciências da Educação (ABSOULUTE CHRISTIAN UNIVERSITY). Pós Graduação em Matemática e Física (FJN). Licenciado em Educação Física (UNILEÃO). Licenciado em Ciências com Habilitação em Matemática (URCA). Bacharelando em Educação Física (UNINTA). EMAIL: tiagosilvacrato@ hotmail.com;

${ }^{2}$ Mestranda em Ciências da Educação (ABSOULUTE CHRISTIAN UNIVERSITY). Pós graduação em Psicopedagogia (Instituto Vale do Soldado). Pós Graduação em Prática de Ensino da Educação Infantil e Ensino Fundamental (FIP). Licenciatura em Pedagogia (UVA). EMAIL: paula.veruskka@yahoo.com.br;

${ }^{3}$ Mestranda em Ciências da Educação (ABSOULUTE CHRISTIAN UNIVERSITY). Pós graduação em Psicopedagogia clínica e Institucional (FCC). Pós graduação em Educação Inclusiva com Ênfase em AEE (FJN). Licenciatura em Pedagogia (URCA). EMAIL: raquelmateus.29@gmail.com;

${ }^{4}$ Mestranda em Ciências da Educação (ABSOULUTE CHRISTIAN UNIVERSITY). Pós graduação em Psicopedagogia (UVA). Licenciatura Plena em Pedagogia (UVA). EMAIL: edilne.mlbs@ hotmail.com;

${ }^{5}$ Mestranda em Ciências da Educação (ABSOULUTE CHRISTIAN UNIVERSITY). Pós graduação em Docência do Ensino Superior (Faculdade Católica); Especialização Infantil, Língua Portuguesa e Artes pela URCA e Licenciatura em Língua Portuguesa (Estácio).alves.rayanna@gmail.com.
} 


\section{Introdução}

A capoeira nos tempos atuais vem crescendo em quantidades de adeptos a sua prática, tanto no Brasil como em outros países, trabalhando elementos como: disciplina, história, cultura, dança, arte, luta, psicomotricidade, saúde, lazer e educação. A capoeira é um esporte muito completo, unindo: força, flexibilidade e equilíbrio num jogo que é quase uma dança, não fossem pelos golpes deferidos pelos capoeiras (PORTO, 2010).

$\mathrm{Na}$ linha de raciocínio do autor, começa a procura por argumentos científicos para a origem da palavra capoeira (Vindo da Língua Tupi), onde segundo alguns historiadores portugueses terem visto índios jogando capoeira. "Apenas para não deixar de comentar o significado da palavra "capoeira" (CAÁPUÉRA) é um vocábulo Tupi-guarani, e significa "mato ralo" ou mato que foi cortado" (PORTO, 2010).

Considerando que são muitas histórias da origem desta arte capoeira, uns acreditam e defendem que ela veio da África na vinda dos africanos ao brasil, no período da escravidão, utilizando os mesmos para mão de obra escrava nos engenhos de cana de açúcar e como também atividades domésticas nas casas do patrão, estes escravos traziam da sua terra natal suas origens e culturas, suas tradições e conhecimentos, inclusive a capoeira. Mas também em contrapartida em pesquisas sobre a origem da palavra capoeira, encontramos indícios da mesma ter sido oriunda dos povos indígenas, levantando consideravelmente a não constatação real da existência da luta semelhante a capoeira na África que comprove sua existência anterior a vinda destes povos para o Brasil.

Segundo Araújo (1999), que a forma primitiva da capoeira chegou ao Brasil com os negros bantus, originários da África Ocidental. Siega (2002), em seu artigo "Capoeira uma abordagem histórica" conta que "após o descobrimento do Brasil, os portugueses necessitavam de mão-de-obra barata para o cultivo da terra e a exploração das riquezas naturais". Após várias tentativas fracassadas com os índios, foram trazidos então os negros africanos. Para Siega (2002, p. 11), mal nutridos e submetidos a uma condição sub-humana, os negros eram guardados nas senzalas, após árdua jornada de trabalho. No seu tempo livre, à noite, cultivavam as suas danças e tradições como forma de lazer e de diminuir um pouco as saudades da pátria africana (PORTO et. al, 2010).

Segundo alguns mestres de capoeira, entre eles um de suma importância para capoeira em sua construção histórica, folclórica e reconhecimento da arte como luta em horas de aflição, tornou este mesmo a luta em metodologia de ensino em academia, uniformizou os adeptos, 
chamou a mesma de Capoeira Angola, defendendo ela como "Capoeira veio da África, africano quem lutou", este mesmo de nome Vicente Ferreira Pastinha, conhecido nas rodas de capoeira como Mestre Pastinha, aprendeu capoeira com um velho de nome Benedito, que um certo dia chamou um menino franzino e pequeno que apanhava todo dia de um menino maior de sua comunidade, o senhor o convidou para deixar de soltar pipa na rua para aprender uma luta que faria com que Vicente parasse de apanhar do menino. Vicente Ferreira aceitou e aprendeu com o senhor sábio a luta para sobrevivência na rua para futuramente se tornar o saudoso mestre que ajudou a tornar a capoeira junto com outros conhecedores da arte o que ela é hoje e se tornou atividade praticada no mundo inteiro e uma das maiores difusoras da língua portuguesa do Brasil fora do País (BREGOLATO, 2007).

Dentre muitos mestres que contribuíram para a capoeira ser o que é hoje, e o que ela foi em relação a notável luta pelo respeito a igualdade de etnias diferentes, uma grande e relevante arma pela libertação dos escravos na época da escravidão, não podemos deixar de enfatizar o nome Manuel dos Reis Machado, conhecido nas rodas de capoeira como Mestre Bimba, ensinou da roça do lobo até o engenho de brotas em Salvador, aprendeu esta luta com Nozinho Bento, também conhecido como Bentinho por volta de 1911, fundando a primeira academia em 1932, com o nome Centro de Cultura Física e Luta Regional Baiana (FILHO, 1997).

Mestre Bimba criador da Luta Regional Baiana: incrementando a Capoeira angola golpes de outras artes inclusive do batuque (dança que era realizada em pares tentando derrubar o oponente com golpes), praticada pelo seu pai. Enfim os praticantes vigorosos de capoeira antigos eram africanos, onde mestre bimba magnificamente colocou uma metodologia de ensino com regras a serem seguidas determinando um cidadão para a época, por motivos e objetivos de acabarem com o termo capoeiragem, por causa da influência de alunos universitários adeptos a Luta Regional Baiana como era chamada está nova luta, dentre eles, um cearense de nome Cisnando Lima, sendo a pedra fundamental na construção e reconhecimento desta luta inovada (FILHO, 1997).

Nosso trabalho não está direcionado a desvendar e nem compreender o mistério de onde veio esta arte capoeira, mas sim trazer um resgate histórico da mesma valorizando o crescimento intelectual e desenvolvimento construtivo na reformulação da vertente Capoeira Angola a Luta Regional Baiana para entendermos melhor sobre a mesma e sua importância na educação: formal, informal e não formal. Mas o que nos aponta como mais racional é que a capoeira tenha sido criada, desenvolvida e aperfeiçoada entre nós brasileiros (SOARES, 1994). 
A Educação Formal é uma educação que acontece num espaço sistematizado, todo o seu processo e suas atividades são organizadas por toda uma coordenação pedagógica, possui a mesma toda uma busca de desenvolvimento do conhecimento através das disciplinas escolares, atendendo as demandas da sociedade atual, ou seja, uma educação institucionalizada. A Educação Informal surge no decorrer do dia-a-dia, ou seja, é culminância, das ações que acontecem a vida do cidadão, sua função é adaptadora e os conhecimentos são adquiridos e passados de geração a geração, perpassados a gerações futuras. A Educação Não Formal acontece fora dos muros da escola, surgindo, portanto no próprio ambiente de interesse e interação do indivíduo, ela é pouco acompanhada pelo ato pedagógico e suas atividades são desenroladas com ampla variedades, na intenção de atender interesses individuais de determinados grupos, está também recebe influências do mundo contemporâneo. A capoeira hoje anda tanto em ambientes Educacionais dentro dos muros da escola como fora dos muros dela, ajudando na formação de cidadãos e construindo conhecimento histórico, cultural, artístico, social, psicomotor e exercício da cidadania.

O que devemos na verdade é ter a certeza do valor da Capoeira da época antiga até hoje, na cultura e história de um povo Brasileiro, surgida na época da escravidão, tornando-se uma poderosa arma contra os senhores de engenho escravistas e os capitães do mato da antiguidade, para hoje se tornar uma importante ferramenta na educação contemporânea neste novo mundo globalizado (VIEIRA, 2007).

O presente artigo tem como principal objetivo discutir a capoeira na formação cidadã, exercício da cidadania dos adeptos da mesma, verificando através de um resgate histórico contribuições do cariri-cearense: Crato, Juazeiro ou Barbalha; terem adeptos no crescimento da mesma. Sabemos que a Capoeira hoje está presente na Educação: Formal, Informal e Não Formal; falaremos nesta pesquisa um pouco sobre cada uma e seu direcionamento junto a capoeira. O estudo desses espaços educacionais, falando sobre o processo ensino e aprendizagem, apresentam o objetivo de desenvolver o cidadão para enfrentar e superar desafios dos tempos contemporâneos e em paralelo cumpri seu papel para a prática social.

\section{A origem da Capoeira}

O pesquisador Rocha (2002, p.13), fornece algumas pistas relativas à possibilidade da origem indígena da Capoeira, quando cita as Cartas para Portugal e Espanha dos anais das missões Jesuítas no Brasil, dentre elas: 
Cartas; do Jesuíta Antônio Gonçalves para os superiores em Lisboa, em 1735, descreve uma luta em que os índios praticavam antes de qualquer conflito, em forma de dois a dois ao centro usando os braços e as pernas como armas (convento de santo Inácio de Loyola, anais das missões do Brasil. Tomo III, p. 128).

Considerando uma análise de cunho mais crítico em relação as Cartas para Portugal e Espanha, considerando de forma relevante a do Jesuíta Antônio Gonçalves para superiores em Lisboa, em 1735, onde as mesmas descrevem minuciosamente a prática de dois sujeitos, onde os mesmos se manifestam usando as pernas e os braços como armas, sendo esta uma forma muito semelhante a prática da Capoeira, como também ao Judô ou ao Huca Huca (LUSSAC, 2015, p. 4).

Para Santos (1990), a capoeira foi uma invenção do negro na África, onde existia como forma de dança ritualista. Mais tarde, com o processo do colonialismo brasileiro e com a chegada dos negros escravos originários da África, aqui a capoeira apareceu como forma de defesa pessoal dos escravos contra seus opressores do engenho.

Capoeira (1998, p. 34), em sua obra "Capoeira-pequeno manual do jogador” afirmando o mesmo sobre o surgimento da capoeira:

Temos agora uma ideia de como nasceu a capoeira: mistura de diversas lutas, danças, rituais e instrumentos musicais vindos de várias partes da África. Mistura realizada em solo brasileiro, durante o regime de escravidão, provavelmente em Salvador e no Recôncavo Baiano durante o século XIX.

Segundo Reis (1997, p.19), em posição idêntica afirma: “A capoeira é uma manifestação cultural brasileira nascida em circunstância de luta pela liberdade, nos tempos da escravidão".

Analisando a temática capoeira: Angola e Regional ( $\mathrm{O}$ mestre Pastinha e Mestre Bimba), onde estes mestres tinham visão diferentes sobre a origem da capoeira, mestre bimba dizia que "os escravos eram africanos, mas a capoeira é de Santo Amaro e Ilha de Maré Camarado". O mestre Pastinha perpetuador da Capoeira Angola, mais folclórica, maliciosa, cheia de mandinga, jogando com calma no chão ou de pé em movimentos quase em câmera lenta, mas ao mesmo tempo muito perigosa pela agilidade e destreza do praticante, afirmava que capoeira veio da "África e africano quem lutou” (PORTO, 2010).

Considerando sobre a importância também de falar sobre a história da Capoeira do Ceará, exatamente porque a pesquisa envolve as contribuições do personagens do cariri: Crato, Juazeiro ou Barbalha, do estado do Ceará, na Educação utilizando a Capoeira. Temos notas de jornais de apresentação de Mestre Bimba neste Estado. 
Na específica data de 7 de fevereiro de 1955, na capital Fortaleza, na publicação do Jornal o Povo em duas notas sobre a Capoeira. Escrita na primeira nota um destaque exclusivo ao Manoel dos Reis Machado, o fundador da Luta Regional Baiana, um tipo de capoeira que retira os seus adeptos da capoeiragem dos antepassados. A nota dava ênfase aos discípulos de Mestre Bimba como, lutadores, dançarinos e atores, e abordava com exclusividade a vitalidade do saudoso Bimba, que o mesmo aos 55 anos, ainda possuía destreza, agilidade e habilidade para mostrar movimentos em suas apresentações.

Comentando sobre a específica segunda nota do Jornal O Povo, denominada com o título com letra maiúscula dizendo o seguinte: “exibição de Capoerismo, hoje no teatro José de Alencar e o subtítulo trazia, in litteris”. E mais danças de cunho africanos, cânticos, cenas de candomblé, Mãe Raimunda e Mestre Bimba para o povo as tradições da Bahia - ingressos a dez e cinco cruzeiros. A denominação desta apresentação é "era uma noite na Bahia", idealizadas e executadas por baianas e capoeiristas todos no comando de Mãe Raimunda e o saudoso Mestre Bimba.

Cantos dolentes, requebrose, saracoteios, invocação dos deuses africanos, tudo isso as baianas pretendem apresentar com seus trajes típicos. Mestre Bimba (ensina capoeiragem a mais de 800 alunos na Bahia, tem 55 anos de idade e ainda é maneiroso) apresentará ao público seus alunos: Carlos Sena (formado em Finanças), Álvaro Alberto (estudante de engenharia), João Veloso e Orlando dos Santos (estudante de comércio) os quais farão demonstração de capoeira (Jornal o Povo, 7 de fevereiro de 1955).

Analisando os escritos podemos observar que o show feito apresentava duas coisas o candomblé e capoeira numa só ilustração, onde pela nota de jornal as mesmas são de origens africanas. É de suma importância comentar que mesmo com as informações históricas de vadios na capoeiragem, os discípulos de mestre Bimba eram estudantes universitários e profissionais, ou seja para se tornar adepto da Capoeira Regional tinha que ser estudante ou ser trabalhador, tudo isto para evitar que os adeptos se descartassem da ideia de ser marginal como era chamado os capoeiristas da antiguidade, por intenções políticas de branqueamento para desvirtuar a importância da luta capoeira. Manoel dos Reis Machado ao iniciar seu show fazia sua explanação para melhor entendimento e interpretação sem julgamentos dos que assistiam, este tipo de iniciativa é muito utilizada hoje pelos mestres da atualidade virou um traço marcante para o profissionalismo nas apresentações de capoeira.

Antes de começar o espetáculo (evocação das tradições afro-brasileiras) será dada uma explicação [...]. Na primeira parte, Mestre Bimba e seus alunos farão exibição de capoeira, dança, ritmo, [...]. Berinbaus, maracás marcarão os passo e a cadência. Na segunda parte, os figurantes desferirão golpes e contragolpes. E a capoeira como 
elemento subsidiário do jiu-jitsu. Mestre Bimba também participará da luta (Jornal O povo, 7 de fevereiro de 1955).

Esta nota do Jornal o Povo é apontada como o primeiro registro da capoeira do Ceará. Então como foi publicado, a capoeira Regional é de suma importância para a história da Capoeira cearense, enfatizando mais forte ainda que na construção, divulgação e liberação da Capoeira na Bahia, no Brasil e entrando para a história da Capoeira do Ceará, temos uma grande contribuição de um cearense (FILHO, 1997).

\section{Um resgate histórico da Capoeira Angola à Luta Regional Baiana.}

O Vicente Ferreira Pastinha (1889 - 1981), o inteligente "Mestre Pastinha" como era conhecido nas rodas de Capoeira, com sua capacidade extraordinária de comunicação, conseguindo se expressar muito bem sem precisar abrir a boca, nas rodas de Capoeira, explorador indiscutível da riqueza corporal que havia adquirido, com a Luta que veio de Angola. Foi perpetuador da Capoeira Angola, segundo ele (1999) "conhecer as leis do ritual, saber brincar, cantar, dançar, ser malicioso, mandingueiro, são qualidades mais importantes do que a simples eficiência marcial dos golpes", como citou no seu livro: Uma vida pela Capoeira (SILVA, 2003, p.52).

Segundo Vicente Ferreira Pastinha escreveu em sua obra "Capoeira Angola", que o mesmo acreditava não estar muito distante a época em que a capoeira estaria no seu devido lugar de valor, e praticada por uma grande quantidade de adeptos, não pelo seu caráter de luta para se defender de oponentes, mas pelo valor e capacidade de manter um corpo saudável e fonte de juventude (PASTINHA, 1968, P.30).

Mestre Pastinha in Bahia (1999), citado por Bregolato (2007, p. 210) no Livro: Cultura Corporal do Jogo, afirmou: “a capoeira é amorosa não é perversa. A capoeira tem harmonia e beleza de movimento, não quer agredir o outro. É um hábito cortês que criamos dentro de nós. E mandiga de escravo em ânsia de liberdade".

O pesquisador Pires (2002), asseverou que sobre o Centro de Esportivo de Capoeira Angola, fundado por mestre Pastinha:

Em 1952, redigir-se o estatuto do Centro Esportivo de Capoeira (CECA). Paulo Santos da Silva, um dos seus principais idealizadores deixou registrado em seu discurso as premissas básicas do CECA: a base fundamental do nosso centro é a boa conduta. Educação Social, solidariedade humana e sobretudo, a prática do bem, não usando a arma poderosa que é a capoeira a não ser em legítima defesa ou em função da pátria (p.82). 
O autor Oliveira (1989), em seus escritos no livro A Capoeira Angola na Bahia, comentando que:

O mestre angoleiro procura passa para o seu discípulo o culto dos rituais e preceitos existentes na capoeira angola e ao mesmo tempo prepará-lo para defender-se sem interferir no seu potencial de criatividade dotando-o de uma grande dose de malícia, baseado na calma e na velocidade (p. 179).

Para Capoeira (1998), comentando o mesmo que nos ensinamentos de mestre Pastinha e na sua academia se praticava o que ele chamava de estilo tradicional, chamado de Capoeira Angola.

A capoeira vai muito mas além dessas características ela possui a musicalidade poética que possui uma integração com o público conhecidas como chulas ou coro na capoeira angola e coro na regional, com ritmos e balanços corporais específicos para cada estilo de jogo, onde se joga com um movimento e uma resposta do oponente, expressão corporal que usa os limites do corpo ou até desafia a gravidade, o capoeirista toca instrumentos de percussão como: atabaque, pandeiro, agogô, reco-reco e o regente principal de uma roda de capoeira o berimbau, ou seja, um artista de estilo único e livre com aprendizagens múltiplas.

Para Almeida (1994, p.15) afirma que "aos 12 anos de idade, Bimba o caçula de D. Martinha, iniciou-se na Capoeira na Estrada das Boiadas, hoje grande bairro Liberdade. Seu mestre foi o africano Bentinho, Capitão da Companhia de Navegação Baiana”. O Manoel dos Reis Machado começando o seu aprendizado na arte da capoeiragem no "modo antigo", o mesmo era frequentador das rodas nas festas e feiras populares da Bahia, aproveitando às horas vagas de seu trabalho como estivador no cais do porto de Salvador.

O Manoel do Reis Machado comentou no livro (A saga do Mestre Bimba), do pesquisador Almeida (1994, p.17), afirmando que: “em 1928 eu criei completa, a Regional, que é o Batuque misturado com a Angola, com mais golpes, uma verdadeira luta, boa para o físico e para a mente".

Comentando sobre a capoeira e sua relação com Luta Brasileira, Luta Regional e Ginástica Nacional, afirmando também sobre sua força musical própria, podendo se assemelhar a ginástica rítmica. Em 1932, funda a primeira academia destinada ao ensino da capoeira, na Bahia com o nome Luta Regional Baiana, liderada por mestre Bimba. A ginástica brasileira como era a intenção de Manoel dos Reis Machado que a capoeira fosse defendida como uma luta e reconhecida como educação física, há de fundamentar-se na flexibilidade, equilíbrio e destreza, assemelhando a mesma a métodos de ginásticas de outros países com: alongamento, 
aquecimento e movimento, cuja técnica do exercício é os reflexos dos movimentos de sua dança, num molejo chamado ginga, realizadas com um ritmo gímnico e próprio, que brota espontaneamente de dentro para fora, diz Marinho (1982) a ginástica brasileira, idealizada por este autor, absorve a capoeira em toda a sua amplitude e encontra na música afro-brasileira a espontaneidade de seu ritmo (PORTO et. al, 2010).

O Mestre Bimba insatisfeito com a folclorização da luta, demonstradas em praças públicas, comentando o mesmo que a luta que costumava apanhar dinheiro com a boca nas rodas jogadas pelos que assistiam as demonstrações, não valorizavam a luta e jamais com essa visão da capoeira ela se tornaria capaz de enfrentar outras lutas oriundas de outros locais. De acordo com sua declaração na imprensa em 1936 (citada em Abreu, 1999, p.68). Então o Manoel dos Reis Machado desenvolveu um novo estilo de capoeira, tendo retirado dois e feito a inclusão de cerca de 15 golpes em conjunto com alguns que já existiam na capoeira, afirmando ele ter implementado golpes do: batuque, maculelê, folguetos brasileiros, luta grego-romana, jiu-jítsu, judô e savata francesa, somando por volta de 52 movimentos (REGO, 1968, p.33; REIS, 1997, p.133).

Para o pesquisador Macul (2008), acerca das estratégias de divulgar o valor de sua capoeira, temos que:

Mestre Bimba também desenvolveu a cerimônia de formatura nos moldes acadêmicos, com paraninfo e tudo mais, e atraiu a classe alta e a burguesia 'para a capoeira. Fez lutas no ringue desafiando outros lutadores na década de trinta para afirmar a sua capoeira enquanto luta, e entre outros (p. 6).

Rego (1968), citado por Viera (p.136) afirmando que: "contrapondo ao modelo “ortodoxo" de Capoeira, Mestre Bimba irá buscar em pessoas mais informadas possibilidades de idealização de seus objetivos enquanto capoeiristas". Usando os seus aprendizes, que oscilam entre homens rudes do povo e pessoas da elite brasileira, Manoel dos Reis Machado incorporou em si próprio e em seus discípulos os seus planos para o crescimento, desenvolvimento e reconhecimento de sua Luta, os quais lhe forneceram uma extraordinária estrutura e e colocaram em letra de forma o seu nome (SILVA, 2003, p.71).

Considerando também um fato histórico sobre uma outra vertente da história da Capoeira Regional pouco relatada até mesmo pelos alunos de Mestre Bimba, que a origem da Luta Regional Baiana, está intrinsecamente ligada a alguns acontecimentos a partir da década de 30, com a ilustre chegada a Salvador "dum cearense apaixonado pelas artes marciais" como cita o Dr. Decanio um dos poucos a reconhecerem como aluno do Manoel dos Reis Machado que Cisnando Lima transformou a história e reconhecimento desta Luta e de seu maior 
percursor Bimba, onde o mesmo logo ao chegar na Bahia andou nas rodas de capoeira em busca de um mestre capaz de lhe ensinar, a tal afamada em sua terra de origem e misteriosa dança guerreira oriundas dos negros da Bahia. Cisnado com seu critério bastante seletivo para escolha de um grande mestre por ser versátil em jiu-jitsu, tendo o mesmo aprendido com o Mestre Takoo Yano, o mesmo possuía um excelente vigor físico, aperfeiçoado pelos exercícios com pesos, desde sua juventude, praticante assíduo de halterofilismo com pedras, no lugar de pesos de ferro (FILHO, 1997, p. 116).

O Cisnando Lima na sua incessante procura numa roda no Bairro Curuzú, avistou um gigante negro, conhecido nas rodas de capoeira como mestre Bimba, a quem o mesmo logo o escolheu como mestre, pela criteriosa observação incessante na sua busca incansável se impressionou com as habilidades exibidas, pela visível técnica superior as de todos os capoeiristas já até então vistos ao ver o Manoel dos Reis Machado jogar. Como todos os iniciantes adeptos da Luta Regional Baiana eram postos a uma prova de coragem pelo Bimba, Cisnando aguentou o colar de força aplicado envolto ao seu pescoço, aprovado foi o primeiro aluno branco da classe dominante em Salvador, tornando-se um lutador excepcional, por sua coragem, agilidade e força, o novo aluno, idealista e um grande poeta e sonhador, inteligente e bem dotado culturalmente, logo induz o Mestre Bimba a enriquecer o potencial bélico da luta negra, com a implementação de novos movimentos oriundos de outras lutas, no intuito de ampliação de seus recursos pugilisticos, e registrá-la sob uma nova denominação, este batismo disfarçaria a mesma, sua origem de uma atividade legalmente aceita (FILHO, 1997, p.116-117).

Um breve comentário sobre a razão dos feitos de Cisnado aluno de Mestre Bimba, era apenas o sonho de divulgar entre seus amigos, aquela misteriosa e inacreditável arte-marcial africana e eliminar a injusta discriminação e proibição vinda da classe dominante, impedindo uma atividade rica de cultura e tradição, o resultado dessa empreitada foi a conquista da legalidade da capoeira, as custas de uma relação batizada de convivência de um mestre e um aluno com autos dotes, que os mesmos juntos transformaram as tradições africanas, sem modificar o seu ritual (FILHO, 1997, p. 118-119).

\section{A interface entre Capoeira e Educação}

Não podemos deixar de falar e descrever que as atividades teóricas e práticas do tipo de educação formal possui como o maior objetivo a obtenção e desenvolvimento dos conhecimentos que estejam em paralelo com as necessidades do mundo contemporâneo. Então 
pela afirmação temos que este tipo de educação está sendo mais idealizada em ambientes educativos chamados de escolas, onde nos mesmos podemos considerar que existe um conhecimento a ser repassado de professor para aluno, numa atividade que chamamos de ensino-aprendizagem, da seguinte forma quem ensina é a figura do professor e quem aprende é a figura do aluno. Podendo delimitar que pelo que observamos em lei o formato deste processo de ensino pode ter diferenças de um espaço formal para o outro, no considerar das características regionais, culturais, econômicas e necessidades da clientela (OLIVEIRA, 2009).

Relacionando a Capoeira como Conteúdo histórico do Brasil de forma crítica Segundo Coutinho (1993, p.18), falando sobre o resgate histórico da Capoeira comenta o mesmo que a Capoeira é uma construção histórica brasileira, sendo, portanto, uma representação de nossa cultura. Suas raízes são africanas, mas nasceu aqui no Brasil, nas misturas de várias etnias que fizeram e fazem parte de nossa rica formação cultural, isto nos pode dar um suporte no cumprimento da lei de considerar os conteúdos com as relações culturais da região ao qual se trabalha a escola. A capoeira é afro-brasileira como já defendida por vários autores que escreveram sobre a história dessa arte, é mestiça, como também é mestiço o povo brasileiro. Mestre Noronha, capoeirista do século XIX, explica que "A capoeira veio da África, porém não era educada. Quem educou ela fomos nós os baianos para defesa pessoal". Podendo está mesma fazer parte do engrandecimento da educação formal da Bahia em cumprimento da lei 9394/96: que institui o ensino curricular no Brasil, inclusive história do nosso povo Brasileiro com suas culturas e características regionais.

A Lei federal de $n^{\circ} 10.639$, de 9 de janeiro de 2003, trata da obrigatoriedade da inclusão de temas da cultura afro-brasileira nos currículos de ensino fundamental e médio das redes públicas e privadas de educação no Brasil. Entretanto, os debates sobre essa questão já vinham sendo desenvolvidas há algum tempo em encontros entre intelectuais e agentes culturais, podendo ser interdisciplinarizada com a capoeira de na educação formal (BRASIL, 2003).

Segundo Bregolato (2007, p.190), em relação ao tema Capoeira e Educação, a proposta do Ministério da Educação e Cultura no ano de 1999 com relação a inserção da Capoeira no Currículo da Educação Física escola, forte apelo Histórico cultural com formato dinâmico, a capoeira Angola pode ser um elemento importante ao integrar-se a um programa de Educação Física escolar, e segundo os Paramentos Curriculares Nacionais que:

A disciplina em questão precisa buscar sua identidade como área de estudo fundamental para a compreensão e entendimento do ser humano enquanto produtor de cultura. Significativa e de caráter lúdico, a Capoeira se bem direcionada representaria um ganho substancial à cultura corporal auxiliando no desenvolvimento e formação do aluno, trabalhando em cima de valores éticos e cooperativos, dando 
liberdade, criatividade e elevando a autoestima de seus praticantes. Indo ao encontro dos interesses da nossa visão de Educação que pede que se traga para a escola elementos da vida cultural do povo (...)" (BRASIL, 2003, p.27).

Para Burihan (2003, p. 36), na visão cultural em todo seu aspecto artístico é a própria expressão de Arte - Luta. Os adeptos da Capoeira Angola que foi percussora para o surgimento da Capoeira Regional, o praticante aprende a: cantar, tocar instrumentos, dançar, teatralizar, dentre outras capacidades e habilidades que ela desenvolve. Sendo assim, se a educação tem o objetivo educacional de desenvolver a arte em sala de aula, pode sim se aproveitar da Capoeira e utilizar a mesma como ferramenta pedagógica, porque no mundo da Capoeira Angola e como percussora da Regional, então consequentemente as duas vertentes, nós professores e colaboradores da educação, devemos desenvolver incentivando no surgimento de novos adeptos com capacidades artísticas populares e agentes perpetuadores da nossa cultura afrobrasileira, indígena e brasileira.

Então para a educação formal buscar parcerias com outros espaços e formas educacionais, o ambiente escolar deve fazer a análise e buscar entender em primeira oportunidade as características desses outros ambientes, seus objetivos, quais finalidades educacionais e científicas buscam. E com as informações levantadas que os ambientes se completem nas áreas do conhecimento.

Considerando alguns exemplos de outros ambientes educacionais, que podem ajudar na educação formal e abrir parcerias na construção do conhecimento, temos: Revistas, jornais, televisão, rádio, organizações não governamentais, museus de Ciências, zoológicos, jardim botânico, hortos, parques florestais, reservas naturais, zona rural, matas ciliares, indústrias, fábricas e implementando também ambientes informais. Ambientes estes que abrem interdisciplinaridade com outras áreas trabalhadas numa sala de aula, onde o aluno, perante estas situações distintas possa pensar, raciocinar, falar e redimensionar seu conhecimento (MARANDINO, 2009).

A importância da Educação Informal é de tal tamanho, no mesmo grau de significado para o ensino-aprendizagem como as demais formas de educação que descrevemos nesta pesquisa, na verdade ela é a primeira educação que o indivíduo recebe dada com os pais e as mães, estes magníficos seres neste cenário educacional são os pioneiros na arte de ensinar. Um dos autores magníficos da área da educação que podemos usar neste contexto é o Libâneo (2010), onde todas as pessoas serão alvo de algum tipo de educação, este comentário nos dar a entender que o meio social ao qual o ser humano vive o influenciará, onde temos que: 
$\mathrm{Na}$ casa, na rua, na igreja ou na escola, de um modo, ou de muitos, todos nós envolvemos pedaços da vida com ela: para aprender, para ensinar, para aprender e ensinar. Para saber, para fazer, para ser ou para conviver, todos os dias misturamos a vida com educação. Com uma ou com várias: educação? Educações, (...) não há uma forma única nem um único modelo de educação: a escola não é o único lugar em que ela acontece e talvez nem seja o melhor; o ensino escolar não é a única prática, e o professor profissional não é seu único praticante (LIBÂNEO, 2010, p. 26).

Então, considerando as colocações do pesquisador Libâneo (2010), a educação acontece não em um único ambiente, isto porque um indivíduo frequenta por toda sua trajetória de vida, diferentes ambientes sociais, a educação informal é ocorrida perante todas as ações, influenciadas por um meio cultural no seio da família, nas relações fora de casa, nas fábricas, nos meios de informação, na política e na religião.

Na obra "Capoeira, Identidade e Gênero de Oliveira e Leal (2009, p. 56), comentam:

A Capoeira tornou-se um fenômeno inusitado de representação da identificação nacional às avessas. Ou seja, carrega em si o paradoxo de ser marginalizada pelos diversos projetos nacionais e ao mesmo tempo um instrumento incomparável de divulgação da história e da cultura brasileira pelo resto do mundo. Além disso antes mesmo de qualquer debate político ou acadêmico sobre o assunto, a Capoeira já era em sua vivência o ensino, um meio excepcional de ação afirmativa da identidade brasileira, em especial aquela produzida pela experiência do negro do Brasil.

Para Freire (1978) traz a vertente de valoração da classe menos favorecida, de sua história e cultura, fundamenta-se na escola baseada na linhagem Humanista tão defendida pelo Paulo Freire um educador com grande contribuição para educação do mundo, onde está concepção é incorporada da justiça em sociedade, do crescimento e expansão da classe oprimida, fundamentada na igualdade de oportunidades para todos. Hoje toda esta linhagem de estudo pode ser interdisciplinaridade do tema inclusão.

Sérgio Burihan (2003, p. 37), enfoca aspectos de suma importância da Capoeira na sua prática pedagógica e metodológica, aspectos e contribuições que podem direcionar o discente como adepto para se integrar de modo positivo num mundo social tão conturbado e excluso:

(...) nossa cultura, pode agora nos ser muito útil, já que anda um tanto descaracterizada devido aos padrões ditados pela globalização. E segundo os últimos acontecimentos do mundo como atentados terroristas, o desrespeito aos direitos humanos e com o crescimento da desigualdade social nos informando que o homem se distancia cada vez mais de um ideal solidário e afetuoso. Por ser um jogo de "camaradagem" e no "respeito" e que privilegia a harmonia. Onde se joga "com um parceiro e não contra um adversário", acreditamos que a Capoeira Angola possa ser um forte instrumento de resgate aos valores culturais e éticos aliados ao processo de construção de um ser mais educado, crítico, criativo, consciente e enfim muito mais íntegro em sua expressão de viver. 
A Lei de Diretrizes e Bases da Educação Nacional, n 9394/96, expressa o avanço dessa percepção, transcrito em seu artigo 1 ${ }^{\circ}$ : “A educação abrange os processos formativos que se desenvolve na vida familiar, na convivência humana no trabalho, nas instituições de ensino e pesquisa, nos movimentos sociais e organizações da sociedade civil e nas manifestações culturais".

Para Gooh (2011), a educação não formal ocorre hoje dentro de lugares como: associações de bairros, nas organizações que englobam s movimentos sociais e os estruturam, nos partidos políticos, nos sindicatos, nas igrejas, nos espaços culturais, nas ONGs, nos espaços de interação na escola formal com a sociedade e etc. Nesses ambiente não formais, existe o respeito pelo tempo de aprendizagem de cada um indivíduo, existindo uma flexibilidade de conteúdo. Outro aspecto importante é que com as ações coletivas no seu principal objetivo transforma o indivíduo para cidadania, ou seja, "a criatividade humana passa pela educação não formal".

Segundo o Mestre Morais um dos perpetuadores da Capoeira Angola atualmente, em vários depoimentos orais sobre o ensinamento que circunda a tradição da capoeira, passada de mestres pra discípulos, ele comenta e denomina como "pedagogia do africano", onde se fundamenta-se no mestre ensina pegando na mão, "O mestre toca o aluno para passar o sentimento... ele não toca unicamente para consertar o movimento... o educador passa mas a vontade de ver o aluno aprendendo, do que a preocupação com a técnica correta". Essa pedagogia de perpetuar o conhecimento a ser ensinado é consumada pela aproximação existente entre o mestre e o aprendiz. Uma proximidade corpo a corpo em que a afetividade, a atenção e a solidariedade do mestre se enfatiza continuamente numa educação não formal (ABIB, 2006, p. 86- 98).

Segundo Gohn (2006) discutindo importantíssimas características pedagógicas direcionadas aos processos na Educação não formal, afirmando que: é aquela em que os aprendizes assimilam via troca de experiências, em espaços e ações em conjunto dia-a-dia fundamentadas de culturas e valores próprios; o mestre de Capoeira é o outro, aquele com que temos contatos integrais e interagimos constantemente, em uma ambiente educativo que acompanham as vidas cotidianas dos indivíduos, ou seja, fora de um ambiente escolar, lugares onde possui processos interativos intencionais, conduzidos por diretrizes de dados grupos.

A Educação não formal não substitui a educação formal, elas se complementam em seus devidos ambientes, uma resolvendo a problemática da outra, na medida que uma desenvolve as competências e habilidades na formação cidadã para o exercício da cidadania, que servirá pra 
o desenrolar da inclusão do ser humano em outras modalidades de ensino. Afinal é na modalidade escolar que os saberes científicos são sistematizados, favorecendo ambas pela construção dos conhecimentos (GOOH, 2006).

\section{Procedimentos Metodológicos}

Visto que serão usados para o desenvolvimento desta pesquisa, material já elaborado, constituído principalmente de artigos científicos. Originário de fontes secundárias, abrange toda bibliografia já tornada pública em relação ao tema escrito. A pesquisa aqui levantada tem caráter bibliográfico por ser também um estudo histórico sobre a interface entre a Capoeira e Educação.

A população e a amostra da pesquisa é qualitativa, possui um levantamento teórico sobre a capoeira e a educação pelo motivo de ser uma pesquisa descrevendo através desta relação conjunta, momentos e autores importantes que nos deixaram informações relevantes sobre o crescimento da Capoeira na formação do cidadão no exercício de sua cidadania, então levantada informações sobre o assunto para considerar e alavancar o questionamento sobre o mesmo, assim despertando da importância da arte genuinamente afro-brasileira nos ambientes educacionais formais, informais e não formais.

A pesquisa foi realizada com material que abrange sobre os assuntos: capoeira como resgate histórico, capoeira como ginástica brasileira e nacional, capoeira na escola e fora dela; fizemos levantamentos históricos para buscar informações teóricas e práticas na metodologia da capoeira para educação, no intuito de levantarmos argumentos que se assemelham as características de além de cultura, dança, arte, história e luta nacional, devem ser implementadas nas escolas e faculdades como ferramentas de ensino-aprendizagem e resgate da cultura afrobrasileira.

Foram utilizados para as escolhas desses artigos aqueles que mais se adequavam ao que se desejava questionar e levantar informações teóricas suficientes sobre o assunto, buscamos pesquisas e artigos científicos sobre o tema capoeira e sua história, suas contribuições para educação, luta e identidade cultural afro-brasileira, analisando os autores que argumentam adequadamente ao objetivo traçado, pesquisadores indicados por mestres de capoeira em cursos de formação e em encontros de eventos desta arte, no intuito de ser o mais claro possível para não chegar as contradições que surgem em relação ao estudo sobre a capoeira e sua importância na educação do Mundo Contemporâneo, depois da leitura destes artigos e livros encontrados

571 Id on Line Rev. Mult. Psic. V.14, N. 50 p. 557-577, Maio/2020 - ISSN 1981-1179 Edição eletrônica em http://idonline.emnuvens.com.br/id 
nas buscas das pesquisas, escolhemos os autores mais simples possível de argumentos nos assuntos, buscando além disso a importância da mesma para a formação da sociedade, cultua e cidadania.

\section{Apresentação e Discursão dos Resultados}

É de suma importância a influência histórica encontrada nas pesquisas, para o crescimento e evolução da capoeira para se tornar luta e metodologia de ensino na educação, como figura importantíssima neste processo o aluno de mestre Bimba, Cisnando Lima como é conhecido no mundo da Capoeira, conterrâneo da cidade de Crato, estado Ceará. Sendo assim devemos considerar a forte contribuição regional do cariri para o crescimento da Capoeira hoje praticada no Brasil e difundida no Mundo, este aluno é citado pelo mestre Decânio, o discípulo mais antigo de mestre Manoel dos Reis Machado (Bimba), o aluno cearence é citado por Decânio como pedra Fundamental da Luta Regional Baiana (Capoeira Regional), este fato relevante foram citados nos livros: A Herança de Mestre Bimba e Capoeira Regional: a escola de Mestre Bimba ( FILHO, 1997).

No mundo da capoeira afirmam que a capoeira veio da África, junto com as navegações de negros para serem escravizados para mão de obra na época colonial, mas até hoje não se comprova a existência de uma dança igual a capoeira na África que comprove o que os mestres de capoeira mas antigos afirmam em palavras repassadas de geração a geração aos discípulos na capoeira, como também cantada em músicas na mesma, onde também denominação de um estilo de capoeira Angola (PORTO et.al, 2010).

Em contrapartida, alguns historiadores antigos escreveram afirmando terem visto tribos de índios jogando capoeira, não deixando de ressaltar sobre a hipótese que os africanos em seu país de origem eram um povo urbano, também a afirmação de alguns historiadores como o mestre Armandino discípulo de mestre Morais grandes resgatadores do estilo Capoeira Angola, afirmando que tribos indígenas invadiam navios tumbeiros em portos brasileiros para buscarem aliados na luta contra a escravidão imposta pelos portugueses, ou seja, esses africanos aprenderam a viver e sobreviver na mata com os índios e lutarem também, inclusive aprendiam rasteiras e ponta- pés, inclusive a denominação da palavra capoeira, oriunda da língua tupi (PORTO, 2010).

A Capoeira teve duas grandes personalidades, os mestres como: Pastinha e Bimba como eram e são conhecidos no mundo dessa arte afirmavam que capoeira veio dos africanos e como 
também foi originária no Brasil, lutaram para a capoeira estar viva e atuante até hoje, Pastinha da Capoeira de Angola (lenta e lúdica) e Mestre Bimba criador da Luta Regional Baiana ( rápida e objetiva jogada mais rápida), esse segundo mestre de capoeira foi muito importante para o crescimento da capoeira, ajudado por um aluno de nome: Cisnando Lima universitário da primeira turma de medicina da Bahia, nascido em terras cearenses (CAMPOS, 2009).

A capoeira possui muitas características como: dança, história, cultura, luta esporte e educação. Para Siega (2002, p. 11), dança camuflada pelo samba para esconder a luta de senhores feudais em épocas da existência de senzalas e escravidão, onde restavam apenas momentos de festejos para alegria de um povo forçado a trabalhar e viver como escravos. Segundo Porto (2010), história de formação de um povo brasileiro e de luta contra a escravidão, onde a única arma eram os pés e as mãos na arte capoeira, cultura afro-brasileira ou africana. Para Campos (2009), luta de libertação, esporte metodizada e de academias depois da sequência de mestre Bimba com a luta regional baiana para driblar a proibição constitucional da capoeira e educação com a lei:10639/03(2003) - artigo 26, que institui e torna obrigatória o ensino da história da cultura afro-brasileira no currículo escolar (PAULA E BONFIM, 2014).

A capoeira vai muito mas além dessas características, ela possui a musicalidade poética que ocorre uma integração com o público conhecidas como chulas ou coro na capoeira angola e coro na luta regional baiana, com ritmos e balanços corporais específicos para cada estilo de jogo, onde se joga com movimentos motores chamados de perguntas do jogador e respostas do oponente, expressão corporal que usa os limites do corpo ou até desafia a gravidade, o capoeirista toca instrumentos de percussão como: atabaque, pandeiro, agogô, reco-reco e o regente principal de uma roda de capoeira o berimbau, ou seja, um artista de estilo único e livre com aprendizagens múltiplas (PORTO, 2010).

A capoeira hoje é um esporte e educação de grande importância para complementar o ensino-aprendizagem, respeito as diferenças, valorização da cultura de um povo, cumprimento de regras, determinação, dedicação e superação, qualidades essenciais hoje para a formação de um cidadão no exercício de sua cidadania. Além disso, trabalha a coordenação motora, agilidade, flexibilidade e psicomotricidade, ou seja, um corpo e uma mente mais saudáveis (PORTO, 2010).

A capoeira é o segundo esporte mais antigo do Brasil, perdendo só para a peteca jogada pelos índios que não é usada hoje como esporte. Então pelo motivo dela possuir algumas características atualmente depois da transformação de ensino criada e idealizada por Mestre Bimba, até hoje ainda existe apesar de em alguns momentos da história ter sido proibida, possui 
uma riqueza inigualável de ensino composto por alongamento, aquecimento e treinamentos em um molejo envolvente sobre uma base de nome ginga acompanhada por uma musicalidade de ritmo forte na mistura com instrumentos de batuques e cordas, diferenciando da ginástica ritma apenas na música ao vivo que a dança possui (MARINHO, 1982).

A Capoeira independente de ser brasileira ou africana, ela já é muito forte no sangue brasileiro e a regional de mestre Bimba foi criada no Brasil por um mestre brasileiro, que com a ajuda de um aluno também brasileiro de nome Cisnando Lima um cearense da cidade de Crato, fazendo com que esse esporte muito mais que um jogo, não perdendo também o seu valor histórico e cultural, seja considerado uma Luta e educação, por se assemelhar aos métodos de ginásticas nacionais hoje estudadas como: sueca, alemã e outras, também sendo considerada por alguns autores como Ginástica Nacional (FILHO, 1997).

A capoeira pode e deve muito bem ser incluída nas escolas e fora dos ambientes escolares, amparada pela lei 10639/03(2003) - artigo 26, “que institui e torna obrigatória o ensino da história da cultura afro-brasileira no currículo escolar", ajudando na formação de um cidadão crítico e com capacidades, desenvolvendo habilidades de transformação de uma sociedade consciente e cidadãos saudáveis, como também sendo inclusa nos níveis superiores do Brasil e quem sabe nacionais, por possuir características próprias e semelhantes a ginástica nacional e depois da metodologia da Regional de Bimba, ser um esporte e luta com suas características educativas para um curso de licenciatura em educação física como uma ferramenta a mais para busca de aprendizagens múltiplas e significativas, trazendo também saúde e bem estar, se adequando muito bem a área da formação cidadã, estando a mesma incluso os cursos de educação física nas universidades e faculdades brasileiras, como também na Educação informa e Não Formal em ambientes não escolares (PAULA E BONFIM, 2014).

\section{Considerações Finais}

Tomando as afirmações teóricas de pesquisas bibliográficas, realizadas com os artigos relacionados a capoeira em suas atribuições históricas e importância educacional, como também no âmbito da formação cidadã no mundo contemporâneo, chegamos a acreditar que a formação acadêmica deve trabalhar o tema abordado, que os profissionais de Licenciatura em História e Educação Física tenham contato com pesquisas relacionadas ao assunto e considerem a capoeira historicamente falando como patrimônio brasileiro e pedra fundamental na educação social de forma prática.

574 Id on Line Rev. Mult. Psic. V.14, N. 50 p. 557-577, Maio/2020 - ISSN 1981-1179 Edição eletrônica em http://idonline.emnuvens.com.br/id 
Acredita-se a partir das pesquisas levantadas sobre a capoeira de angola até a luta regional baiana, que a mesma e este tema é de suma importância para ser desenvolvida nas escolas e fora delas, considerando ela como Luta, cultura e esporte. Tendo o tema uma forte relação com o ensino-aprendizagem escolar e não escolar, cultura corporal, desenvolvimento da disciplina, identidade, levando em consideração que a roda da capoeira e sua evolução ao longo destes tempos uma vivência de respeito a diversidade cultural no meio social em vivência um com os outros.

Não deixando também de dar créditos mais ainda o assunto e sua referência teórica neste artigo, ser de grande relevância para o desenvolvimento motor e psicológico dos discentes, melhorando a aprendizagem dos mesmos, trabalhando em aulas metodológicas: teóricas e práticas, tanto na formação acadêmica como também na vida escolar do discente amparada pela Lei: 10.639/03 e a 9394/96, desenvolvendo a afetividade, respeito, determinação, dedicação, controle da agressividade, inclusão e ampliar o conhecimento do docente e do aluno, causando assim impactos positivos na mudança do comportamento em relação ao respeito pela diversidade do nosso povo e com grande relevância do não preconceito racial que existiu antigamente na evolução do mundo, onde comparando a capoeira viveu uma época chamada de escravidão e hoje ela já passou por um processo evolutivo pra luta e respeito a diversidade.

Levando também em consideração que independentemente de onde a capoeira veio se foi da África ou foi criada no Brasil, hoje ela já possui sua força como: dança, ginástica, luta, esporte, cultura, arte marcial, história e hoje educação, possuiu sua resistência em épocas de escravidão e lutou contra ela, através de seus praticantes escravos e índios. Como também outros brasileiros em tempos de guerras para defender o País. Hoje sua força é bem maior levada para as academias se idealizando como educação não formal, com o seu ensino didático, nas figuras de grandes mestres como: Pastinha e Bimba, onde os dois demonstraram e defenderam que a capoeira é inclusão e respeito mútuo ao outro, sem se preocupar com distinção de cor ou religião, a capoeira trabalha a psicomotricidade, tornando o seu praticante um cidadão mas forte e saudável, no exercício de sua cidadania como atuante e ser transformador de uma sociedade globalizada.

\section{Referências}

ABIB, P. R. J. Os velhos Capoeiras ensinam pegando na mão. Cad. Cedes, Campinas, Vol. 26, n. 68, p. 86-98, jan./abr. 2006. Disponível em: http://www.cedes.unicamp.br. 
ALMEIDA, R. C. A. A saga do mestre Bimba. Salvador: Ginga Associação de Capoeira, 1994.

BRASIL, Ministério da Educação e do Desporto. Secretaria de Educação Fundamental, 2003.

BREGOLATO, R. A. Cultura Corporal do Jogo. São Paulo: Icone, 2007 (Coleção educação física escolar: no princípio de totalidade e na concepção histórico-crítica Social; v.4).

BURIHAN, S. J. Capoeira Angola: um jogo, uma brincadeira de roda. Monografia (Licenciatura em Educação Física) -Faculdades Integradas Módulo; Caraguatatuba, 2003.

CAMPOS, H. Capoeira regional: a escola de Mestre Bimba/ Helio Campos (Mestre Xáreu). Salvador. EDUFBA, 2009.

CAPOEIRA, N. Capoeira: pequeno manual do jogador. 4. ed. Rio de Janeiro: Record, 1998.

COUTINHO, D. A Capoeira angola: manuscrito do mestre Noronha. Brasília: DEFER, 1993.

FILHO, A. A. D. A Herança de Mestre Bimba. Editoração eletrônica do texto,, revisão, criação e arte final da capa. $2^{a}$ edição, 1997.

FREIRE, Paulo. Cartas à Guiné-Bissau: registro de uma experiência em processo. Rio de Janeiro: Paz e Terra, 1978.

FREITAS, J. L. Capoeira na Educação Física: como ensinar? Curitiba: Editora Progressiva, 2007.

GOOH, J. L. Educação não formal, participação da sociedade civil e estruturas colegiadas nas escolas. Revista Ensaio - Avaliação e Políticas Públicas em Educação, Rio de Janeiro, Fundação Cesgranrio, v. 14, n. 50, p. 17 - 38, jan./mar, 2006.

GOOH, J.L. Educação não formal e cultura política. ed. São Paulo: Cortez, 2011 c.

GOOH, M. G. Educação não-formal, participação da sociedade civil e estruturas colegiadas nas escolas. Ensaio: aval. pol. publ. Educ., Rio de Janeiro, v. 14, n. 50, p. 27-38, Jan./Mar. 2006. Disponível em http://www.Scielo.br/pdf/ensaio/v14n50/30405. pdf. Acesso em 22/ de Set. 2018.

LIBÂNEO, J. C. Pedagogia e pedagogo, para quê? 12. ed. São Paulo: Cortez, 2010.

LUSSAC, R. M. P. Especulações acerca das possíveis origens indígenas da capoeira e sobre as contribuições desta matriz cultural no desenvolvimento do jogo-luta. Rev. bras. Educ. fís. Esporte vol.29, n .2, São Paulo. Apr./june, 2015.

MACUL, M. V. S. Capoeira: luta de resistência à violência. Boletim Interfaces da Psicologia da UFRuralRJ-2 Seminário-Ano 2008.

MACIEL, K. F. O Pensamento de Paulo Freire na trajetória da educação popular. Educação em Perspectiva, Viçosa, v.2, n.2, p. 326-344, jul./dez. 2011.

MARANDINO, M. SELEES, S. E. FERREIRA, M. S. Ensino de Biologia: histórias e práticas em diferentes espaços educativos. São Paulo: Cortez, 2009.

MARINHO, I.P. A Ginástica Brasileira-Resumo do Projeto geral. Brasília, $2^{\text {a }}$ edição, 1982.

NETO, J. O. F. A história da Capoeira Cearense: da visita de Mestre Bimba aos eventos intelectuais. XII Encontro de Pós-Graduação e pesquisa. Universidade de Fortaleza, 22 à 26 de outubro de 2012. 
O POVO, Jornal de 7 de Fevereiro de 1955.

OLIVEIRA, J. L. (Mestre Bola Sete). A capoeira angola na Bahia. Salvador: EGBA, Fundação dos Antes, 1989.

OLIVEIRA, R. I. R. GASTAL, M. L. Educação Formal da Sala de Aula- Olhares sobre o Ensino de Ciências utilizando espaços não formais. In: VII ENPEC- Encontro Nacional de Pesquisa em Educação em Ciências, Florianopolis, 2009.

OLIVEIRA, J. P. LEAL, L. A. P. Capoeira, Identidade e Gênero (Ensaios sobre a história social da capoeira no Brasil). Salvador-BA, EDUFBA, 2009.

PASTINHA, V. F. A Capoeira Angola por Mestre Pastinha. Salvador. Edição do autor, 1968.

PAULA, T. R. BEZERRA, W. P. As vantagens do ensino da capoeira nas aulas de Educação Física Escolar. Revista Digital- Buenos Aires. No 188. Enero. 2014. http://www. Efdeportes.com/

PIRES, A. L. C. S. Bimba, Pastinha e Besouro Manganga: três personagem da Capoeira Baiana. Tocantins/Goiania: NEAB/Grafset, 2002.

PORTO, D. S. A Capoeira na cultura brasileira: Um resgate histórico. Revista Digital- Buenos Aires. No 142- Marzo, 2010.

REGO, W. Capoeira angola: ensaio etnográfico. Salvador: Itapuã, 1968.

REIS, L. V. S. O mundo de pernas para o ar. 1997, p. 155-175.

ROCHA, L. C. K. Teses que comprovam a brasilidade da Capoeira. Rev. Prat. Capoeira. 2002, 17:10-3.

SILVA, J. M. F. A linguagem do corpo na capoeira. Rio de Janeiro: Sprint, 2003.

SILVA, A. J. P. A capoeira e a arte da capoeiragem: ensaio socioetmológico. Salvador: Empresa Gráfica da Bahia, 2003.

SOARES, E. B. JULIO, M. G. A Inserção da Capoeira na Formação docente de Educação Física, Pensar a Prática, Goiânia, vol.13, n03, p.01-14, Set/Dez-2010.

VIEIRA, S. L. S. As influências do positivismo e do higienismo nos primórdios da Educação Física e na Ginástica Nacional Brasileira (Capoeira). O mundo da Saúde São Paulo, out./dez. 31(4): 500510, 2007.

\section{Como citar este artigo (Formato ABNT):}

SILVA, Tiago da; LIMA, Paula Veruska Alexandre de; MATEUS, Raquel da Silva; SARAIVA, Edilne Maria Luna Bacurau; SANTANA, Juliana Alves. As Contribuições da Capoeira na Educação. Id on Line Rev.Mult. Psic., Maio/2020, vol.14, n.50, p. 557-577. ISSN: 1981-1179. 